\title{
TRANSFORMAÇÕES NA HISTÓRIA ECONÔMICA: CONSIDERAÇÕES SOBRE AS MUDANÇAS DE MODELOS ECONÔMICOS NO DECORRER DA HISTÓRIA
}

\author{
José D’Assunção Barros'
}

\section{Resumo}

Esse artigo busca desenvolver algumas considerações acerca da História Econômica, do ponto de vista de uma modalidade singular de saber histórico, e de suas posturas metodológicas diante da análise de objetos historiográficos específicos. A questão específica que se toma para análise é a que se refere à reflexão deste campo sobre os modos como se dá a passagem de um sistema econômico a outro, ou de um grande padrão característico de certa época, em determinada espacialidade, a um novo padrão.

Keywords: História Econômica; História Econômico-Social; Economia

Classificação JEL: B00; N01

\section{FATORES ENDÓGENOS E EXÓGENOS: ASPECTOS DE DOIS MODELOS EXPLICATIVOS}

Como surgem ou se processam as transformações nos sistemas econômicos historicamente localizados? A pergunta, colocada desta maneira, pode soar banal. Contudo, podem ser estabelecidas verdadeiras polêmicas em torno das respostas a serem definidas pelas diversas possibilidades de ação dos historiadores e economistas frente à análise de processos e transformações pertinentes aos diversos sistemas econômicos históricos específicos. Uma explicação econômica deve apoiar-se exclusivamente no interior do sistema econômico analisado, ou deve considerar fatores ex-

Professor da Universidade Federal Rural do Rio de Janeiro. Correio: jose.assun@globo.com 
ternos, igualmente importantes para a decifração dos processos históricos a serem examinados? De outro lado, deve a explicação econômica incluir apenas fatos econômicos na sua cadeia explicativa, ou são igualmente importantes os fatos relacionados à Cultura, ao Imaginário, às Mentalidades, ao mundo Político? Ou, por fim, até que ponto um sistema econômico pode ser considerado unificado, ou de que modo se fazem valer as especificidades regionais ou setoriais relacionadas às unidades mais amplas, produzindo singularidades próprias?

Estas perguntas colocam-nos no cerne da recente busca da complexidade pelos desenvolvimentos contemporâneos da História Econômica - considerando-se aqui este campo disciplinar como uma das diversas modalidades historiográficas que adquirem maior impulso a partir da primeira metade do século XX. Nosso objetivo neste artigo será o de examinar como as transformações econômicas têm sido concebidas pelos historiadores e economistas-historiadores em relação aos próprios sistemas e processos econômicos sobre os quais elas incidem, e como daí se tem procurado construir os possíveis processos explicativos.

Partiremos da idéia inicial de que os fatores e aspectos internos - ou "endógenos" - de um determinado sistema ou processo econômico são aqueles que fazem parte do próprio sistema, ou que surgem dele, de seu desenvolvimento, maturação, deterioração, que se desdobram do próprio sistema examinado ou que se redefinem a partir dos próprios desenvolvimentos do sistema analisado. Enquanto isso, os fatores ou aspectos externos - ou "exógenos" - seriam aqueles que vêm de fora do sistema, que surgem como acontecimentos independentes do sistema. Este par de oposições - os fatores endógenos e os fatores exógenos - pode ser iluminado com o recurso de exemplificações, conforme veremos.

Estaremos falando aqui dos modelos explicativos com os quais o historiador econômico trabalha. Buscaremos esclarecer estes parâmetros, ressaltando, contudo, o fato de que diversas das explicações que têm sido elaboradas para os desenvolvimentos históricos de economia, particularmente as explicações mais plausíveis, procuram na verdade contrabalançar no seu processo de argumentação e demonstração fatores exógenos e endógenos, bem como elementos dedutíveis e empíricos. Contudo, considerar as posições extremas pode ser útil para a nossa exemplificação. 


\section{EXPLICAÇÕES EXÓGENAS}

Uma explicação exclusivamente exógena é aquela que propõe como fatores de esclarecimento para a História da Economia, ou para a análise de processos econômicos historicamente localizados, apenas fatores exógenos - isto é, vindos de fora. Guerras, epidemias, fatores meteorológicos - eis aqui uma série de fatores, todos externos à economia, que as teorias exógenas evocam para explicar as flutuações econômicas. Também as flutuações demográficas, desde que não sejam decorrentes do próprio sistema examinado, ou as boas e más colheitas, quando ocasionadas por questões exclusivamente naturais, poderiam ser citadas como fatores externos a um sistema econômico examinado, de modo que temos que nos habituar a ver como "externo" tudo o que não faz parte do próprio sistema considerado, e não necessariamente aquilo que vem de fora da sociedade analisada.

Para as explicações exógenas, são estas excitações e motivações externas que acionariam o processo de transformação econômica, ou mesmo presidiriam seus ritmos e encaminhamentos. Um curioso exemplo de explicação exógena foi dado pelo economista inglês Jevons, que em alguns artigos escritos entre 1875 e 1878 chegou a deslocar para as alterações nas manchas solares o ponto de partida de sua explicação para a regularidade aproximada dos ciclos econômicos. De acordo com Jevons, os efeitos de intensidade decorrentes da atividade solar influenciariam as colheitas, e conseqüentemente ditariam o ritmo da economia com seus ciclos marcados por movimentos de expansão e contração ${ }^{2}$. Conforme podemos ver nesta explicação, a excitação externa e a influência continuada de fatores exteriores é francamente utilizada para explicar os desenvolvimentos econômicos.

A explicação de Jevons, que certamente perseguia obsessivamente a possibilidade de prever desenvolvimentos econômicos futuros a partir de uma observação científica da própria natureza, lança luz sobre o que deve

\footnotetext{
Os textos nos quais Williams Stanley Jevons desenvolve estas idéias são respectivamente The Solar Period and the Prince of Corn (1875); The Periodicity of Commercial Crises and Its Physical Explanation ( 1878), e, finalmente, "Commercial Crises and Sun-Spots" (Crises Comerciais e marcas solares), publicado na prestigiosa revista Nature em novembro de 1878. Este ultimo ensaio foi republicado pelo autor em seu livro Investigations in Currency and Finance (London: Macmillan, 1884). Mais tarde, o filho de W.S. Jevons - H. S. Jevons - ainda insistiria nas mesmas proposições em um artigo intitulado "Trade fluctuations and solar activities" (Contemporary review, August, 1909), terminando por escrever, no ano seguinte, um livro mais completo sobre a questão (JEVONS, H. S. The Sun's heath and trade activity. London: 1910).
} 
ser considerado um fator exógeno em relação a um dado sistema econômico. $\mathrm{O}$ que as manchas solares estariam regendo, naturalmente, seriam as próprias colheitas e desempenho agrícola. $\mathrm{O}$ fator evocado é tão externo - as "manchas solares" - que não paramos para pensar que também o próprio desempenho da natureza, independentemente ou não de sua motivação no movimento dos astros, também pode ser examinado como um fator exógeno ao sistema. Pensemos por exemplo nas grandes propriedades feudais da Idade Média. Não importa se em vista de fenômenos atmosféricos específicos, ou se em vista de deslocamentos singulares das manchas solares, uma boa ou má colheita atingia necessariamente uma sociedade agrícola da época do feudalismo como um raio. Da boa ou da má colheita poderiam depender a fartura ou a carência alimentar, pessoas poderiam sobreviver ou multidões desaparecerem em vista dos desenvolvimentos naturais. A Natureza, neste sentido, no momento em que não é passível de ser controlada pelo sistema, funciona como um fator exógeno, exterior a ele, capaz de orientá-lo ou influenciá-lo de fora.

Muitas vezes somos tentados a enxergar como fatores exógenos a uma explicação econômica os aspectos que não são propriamente econômicos, e que se referem à Natureza, à Cultura, à Política, às Relações Diplomáticas. Mas este ponto requer uma explicação importante. Ainda com relação à possibilidade de considerar fatores exógenos em uma explicação econômica, pode-se evocar uma situação ainda mais sutil. Por vezes, a explicação opera-se dentro do âmbito da dimensão econômica (isto é, sem convocar fatores oriundos do plano político, cultural, demográfico). Contudo, o fator econômico que produz a transformação vem de fora da sociedade que está sendo examinada. Este é o caso, por exemplo, das explicações de Pirenne acerca da passagem do Mundo Carolíngio para a Idade Feudal, ou desta para a Modernidade, pois neste caso o Comércio externo é que funciona como uma espécie de excitação externa que produz as transformações ${ }^{3}$.

Também se situa aí o cerne da célebre querela entre Dobb e Sweezy, pois este último também sustentou sua explicação sobre a passagem para a Modernidade evocando o comércio externo de longa distância como excita-

As teses de Henri Pirenne sobre a transição do Feudalismo para o Capitalismo foram enunciadas em 1922 na Revue Belgue de Philologie et Histoire e publicadas na sua forma definitiva em 1935; mais tarde, foi incluída nos últimos capítulos da obra de Pirenne sobre a História da Europa (Historia de Europa, desde las invasiones al siglo XVI. México: Fondo de Cultura, 1981). 
ção transformadora, enquanto Dobb procurava sustentar sua argumentação evocando exclusivamente fatores internos à própria sociedade examinada, no caso atribuindo uma importância central à mudança das próprias necessidades das elites senhoriais.

Apenas para lembrar essa notória discussão historiográfica sobre as passagens da época feudal à modernidade pré-capitalista, foi no final dos anos 40 e na primeira metade da década de 1950 que se estabeleceu esta interessante polêmica sobre o Feudalismo que ficaria registrada na história da historiografia econômica. Ela envolveu predominantemente autores marxistas da Inglaterra, mas também de outros países, que se ocuparam de discutir os aspectos teóricos daquilo a que se referiam como Modo de Produção Feudal, bem como os aspectos teóricos envolvidos na transição deste modo de produção para um outro, o Modo de Produção Capitalista. O ponto de partida da polêmica foi a obra elaborada por Maurice Dobb em 1946 com o título Studies in the development of Capitalism (1946), sendo que a partir de críticas vigorosas de Sweezy a polêmica tomou a forma de uma rede de "réplicas" e "comentários" publicados em forma de artigos em algumas revistas especializadas como a Economic History Review e a Science and Society. Os principais ensaios que constituem a aludida polêmica foram depois reunidos em uma obra organizada por Rodney Hilton ${ }^{4}$.

Não trataremos aqui desta questão específica, que pode ser consultada a partir da interessante querela que se estabeleceu no diálogo bibliográfico estabelecido pelos diversos autores que se envolveram na polêmica. Apenas a citamos para mostrar que o contraste entre explicações endógena e exógena. Sweezy, à maneira de Pirenne, buscava ancorar sua explicação acerca da passagem do Feudalismo à Modernidade no desenvolvimento do comércio de longa distância, como se este fosse uma excitação externa que começa a desenvolver ou desestabilizar o sistema. Dobb situa este mesmo comércio de longa distância - ou, mais especificamente, a adesão dos grandes senhores feudais a este comércio de longa distância - como um produto, um desdobramento de necessidades oriundas do próprio sistema feudal. O exemplo é interessante porque pode mostrar que um mesmo fator - no

${ }^{4}$ HILTON, Rodney (org.). A Transição do Feudalismo para o Capitalismo, Rio de Janeiro: Paz e Terra, 1989. Particularmente sobre as considerações de Sweezy acerca dos fatores exógenos envolvidos na passagem da economia européia para a Modernidade, ver "Uma Tréplica" (Science and Society. Londres: spring, 1953), que responde a um artigo anterior de Dobb (“Uma Réplica”, Science and Society. Londres: spring, 1950). 
caso o 'comércio de longa distância' - pode ser lido como fator endógeno ou exógeno, dependendo do lugar que atribuamos a este fator em nossa explicação do processo histórico.

\section{EXPLICAÇÕES ENDÓGENAS}

Poderemos avançar, a seguir, para o segundo grupo de procedimentos explicativos mais extremados. Contrastando com as explicações exógenas que evocam fatores de ordem externa para solucionar questões econômicas - freqüentemente ressaltando fatores políticos, culturais, climáticos ou demográficos como detonadores do processo de transformação - já uma explicação endógena, no primeiro sentido que vínhamos considerando, é aquela que procura esclarecer um certo desenvolvimento histórico relacionado à Economia exclusivamente no interior dos próprios fatores econômicos. Por exemplo, consideremos as explicações de História Econômica que costumavam ser desenvolvidas por Juglar - o famoso economista francês do século XIX que estabeleceu como unidade operacional para a identificação dos movimentos econômicos os ciclos decenais ${ }^{5}$. Juglar tendia a fornecer suas explicações exclusivamente através de fatores endógenos de natureza econômica - como as variações de juros, as políticas dos bancos centrais e as modificações no estoque dos metais. Assim, é inteiramente baseada em fatores endógenos, notadamente na questão do monetarismo, a sua explicação para a História da Economia no século XVI - este século que no quadro de tendências seculares constitui sabidamente a um padrão de expansão econômica, aliás marcado por uma subida vertiginosa nos preços. Do mesmo modo as flutuações econômicas que se expressam através dos ciclos da economia capitalista, por ele estudados pela primeira vez de maneira sistemática - merecem uma explicação exclusivamente em termos monetários, considerando como elementos centrais as modificações nos estoques de metais preciosos, a política dos bancos centrais e as variações de juros. Não entram elementos exógenos nesta explicação. Para sermos mais precisos, a explicação é endógena em um duplo sentido: por não considerar fatores extra-econômicos, e por não considerar fatores econômicos exteriores ao sistema que está sendo considerado.

JUGLAR, C. Des crises comerciales. Paris: 1889. $2^{\text {a }}$ edição. 
Consideremos, por exemplo, uma explicação que leve em conta para sua elaboração fatores exclusivamente econômicos que pudessem ser desdobrados uns dos outros (veremos logo que, além de ser uma "explicação endógena", aqui também teríamos um tipo de explicação exclusivamente "dedutiva", já que para ser produzida não leva em consideração dados empíricos recolhidos através de fontes diversas que são submetidos a análises estatísticas). A título de exemplificação, vejamos a seguinte cadeia argumentativa, proposta por Ciro Flamarion Cardoso para esclarecer um plano explicativo exclusivamente endógeno ${ }^{6}$. Uma população que revele a tendência a aumentar a sua poupança em determinado período produz como conseqüência uma redução do consumo; com isto, as vendas caem e aumentam os estoques. Com o aumento dos estoques há diminuição na fabricação dos produtos que já não apresentam a mesma demanda, o que ocasiona uma dispensa de mão-de-obra e uma diminuição nos lucros dos grandes capitalistas. Com a redução dos salários, o processo tenderá mais tarde a estabelecer um equilíbrio entre o consumo e os estoques acumulados. Nesta explicação, não entraram elementos externos, e na verdade o sistema dedutivo também operou por si mesmo sem necessitar da comprovação empírica, o que nos coloca diante da questão do segundo par de fatores a ser examinado nas questões econômicas: a dedução em oposição à indução através de dados empíricos. Se quiséssemos contrastar esta explicação com um outro modelo, poderíamos lembrar que uma 'explicação empírica' apóia-se ou deve se apoiar diretamente nos dados empíricos observáveis, procedendo por uma generalização a partir de casos concretos, normalmente à base de dados levantados e analisados criteriosamente através de métodos estatísticos. Um exemplo está nas obras de Claphan sobre a História da Economia na Inglaterra Moderna ${ }^{7}$, ou nos trabalhos de Mitchell sobre os ciclos da economia financeira ${ }^{8}$. De todo modo, o fato de que um historiador trabalhe a partir de deduções ou observações empíricas - ou de uma combinação entre ambas, o que é o mais comum - não afeta o caráter endógeno ou exógeno de uma explicação.

\footnotetext{
O exemplo é proposto, a título de ilustração para uma análise endógena, por Ciro Flamarion Cardoso em Os Métodos da História (CARDOSO, Ciro Flamarion e BRIGNOLI, Héctor Pérez. Os Métodos da História. Rio de Janeiro: Graal, 1990, p.278-279).

CLAPHAM, J. H. An Economic History of Modern Britain. 3 vol. 1926- 1938.

8 MITCHELL, W. C. Business Cycles. The Problem and its Setting. 1927.
} 
É oportuno ressaltar que o historiador econômico não precisa, e nem deve, situar-se exclusivamente em um destes horizontes explicativos: a consideração de fatores exógenos, ou a consideração dos fatores exógenos. $\mathrm{Na}$ verdade, a complexidade da realidade histórica exige, habitualmente, que se considere elementos e fatores produzidos pelo próprio sistema analisado, e elementos externos ao sistema, pois a História não é feita de sistemas fechados em si mesmos. Não habitualmente. De todo modo, a radicalização de modelos tem em vistas, aqui, apenas clarificar os parâmetros explicativos com que podem lidar os historiadores.

\section{EQUILÍBRIO ESTÁTICO X DINAMICIDADE}

Já que falamos em complexidade histórica, outra dicotomia importante a ser considerada no jogo de parâmetros explicativos à disposição dos historiadores econômicos é a relação entre 'equilíbrio estático' e 'dinamicidade'. Até a década de 1930 predominaram os sistemas econômicos dirigidos para o equilíbrio estático, tendência que foi fortemente abalada pelo impacto da Grande Depressão e por um novo contexto que passa a estimular os economistas e historiadores econômicos a compreenderem melhor o dinamismo das transformações econômicas - em alguns casos visando inclusive a proposta de políticas anticíclicas. Desde então os problemas centrais da história econômica se deslocaram preferencialmente para indagações que levavam em conta, sobretudo, a transformação na temporalidade. A Cliometria, entre outros campos de possibilidades, surge já neste novo quadro de motivações. Mas também surge uma História Econômica-Social profundamente preocupada com a repercussão dos fatos econômicos da vida social. De uma História Econômica cujos objetos preferenciais relacionavam-se ao problema do equilíbrio geral de um mercado de bens e serviços, passa-se a problemas como as relações entre os desenvolvimentos da economia monetária e o pleno emprego, o custo de vida, o empobrecimento populacional e outras questões mais.

A tendência da historiografia econômica, a partir da metade do século $\mathrm{XX}$ é tornar-se mais complexa e equilibrada com relação à consideração de uma série de fatores. Atribui-se importância tanto a fatores exógenos como a fatores endógenos, ao mesmo tempo em que as explicações tendem a entremear de forma equilibrada a dedução teórica e a demonstração empírica, com ampla utilização de metodologias estatísticas mas sem dispensar 
as análises qualitativas. Ao mesmo tempo, considera-se tanto o equilíbrio do sistema econômico como a sua dinamicidade, para além de se lançar problematizações que indagam mais profundamente pela interação entre economia e sociedade. Os próprios dados aparecem mais problematizados. Os historiadores econômicos não se contentam apenas em levantar criteriosamente os dados que estarão expressos em uma curva de preços e salários, mas procuram indagar que significado terão aqueles preços e salários para a sociedade sobre a qual eles incidem. Vão mais além, investigando as repercussões econômicas nos diversos grupos sociais. A História Econômica, assim, torna-se mais complexa.

\section{POR UMA HISTÓRIA ECONÔMICA COMPLEXA}

Exemplo de tratamento complexo da História Econômica pode ser encontrado quando o analista compreende o próprio fato econômico como produto de uma complexidade que transcende a dimensão econômica propriamente dita. Rigorosamente, disto cada vez mais se acerca a moderna História Econômica, não existe o "fato econômico" propriamente dito, isolável de outros fatores, de modo que cada vez mais os pensadores e estudiosos da Economia têm recolocado a questão de que os fatos econômicos freqüentemente acham-se imbricados com fatos políticos, sociais, culturais, institucionais, ou mesmo ligados às mentalidades.

A esse respeito, será oportuno registrar a contribuição da Nova Economia Institucional de Douglass North ${ }^{9}$. Não estaremos examinando aqui as implicações ideológicas da análise de North, que habitualmente é vista como uma análise liberal da História Econômica. Nosso objetivo será apenas o de mostrar que as análises econômicas, independentemente das correntes ideológicas às quais se vinculem, podem buscar a complexidade no tratamento dos sistemas e processos econômicos. Com a abordagem explicativa de Douglas North, ancorada no âmbito de uma leitura institucional da história econômica de cada sociedade, mostra-se precisamente

\footnotetext{
( I) NORTH, Douglass. Empirical Studies in Institutional Change (Political Economy of Institutions and Decisions). New York: Lee J. Alston, 1996 e (2) Institutions, Institutional Change and Economic performance. Cambridge: Cambridge University Press, 1990. Antes destas obras, uma referência também fundamental é Structure and Change in Economic History (NORTH, 198I), na qual North já se propõe a analisar a história econômica, da pré-história à contemporaneidade, através de uma leitura das transformações institucionais. Vale ressaltar ainda, como integrantes importantes da corrente que ficou conhecida como Nova Economia Institucional, os nomes de Oliver Williamson e Ronald Coase.
} 
ressaltada a importância dos aspectos institucionais e, mais ainda, políticos, na constituição dos processos econômicos. Assim, tal como observa North ao considerar os desenvolvimentos do Capitalismo, sobretudo nas suas últimas fases, os sistemas políticos trazem ou devem trazer eles mesmos uma contribuição fundamental para a constituição dos sistemas econômicos, e, de certo modo, pode-se dizer que em muitos casos quem institui as regras do jogo econômico é a Política. Recolocar nestes termos o papel dos sistemas políticos e das instituições para o desenvolvimento dos processos econômicos é examiná-los, na ótica da Economia Institucional, a partir de uma perspectiva mais rica, complexa, interdisciplinar.

As Instituições são aqui vistas também na sua dimensão de estruturas de incentivo, que interferem nos mercados, e não como estruturas que são meramente criadas para ajustar-se a certas funções deste mercado, tal como propunha o institucionalismo funcionalista ${ }^{10}$. Recupera-se, assim, a perspectiva de uma dinâmica de reciprocidade entre Instituições e sistemas econômicos, de modo que as idéias de North orientam-se no sentido de perceber que há uma interrelação entre o crescimento econômico sustentado e o fortalecimento institucional. A solidez das instituições constituiria precisamente um estímulo à produtividade, ao investimento tecnológico, ao aprofundamento da inovação - e aqui seria preciso atentar tanto para as instituições formais (leis impostas pelo governo e instituições reguladoras) como para as instituições informais, que constituiriam normas e códigos de conduta formados pela própria sociedade ${ }^{11}$. Neste contexto, o Estado, ou o sistema político, também teria seu papel fundamental, no sentido de assegurar o ambiente de formação e manutenção das instituições formais.

Uma tal abordagem da História Econômica, atenta às transformações institucionais e políticas que se dão no seio das diversas sociedades, permitiria examinar e esclarecer as diferenças de desenvolvimento econômico que se expressam entre as histórias econômicas dos diversos países, notando-se

\footnotetext{
10 É importante ressaltar que, para North, as instituições incluem uma legislação capaz de assegurar os direitos de propriedade e o cumprimento das obrigações contratuais, bem como um sistema judiciário eficaz e diversas outras agências destinadas à regulamentação em diversos níveis da vida social. Importante ressaltar que, para a questão econômica, as instituições desempenhariam um papel fundamental no sentido de atenuar a 'incerteza' - fator que afeta a possibilidade de transação econômica entre pessoas e que por isso geraria, concomitantemente, o que North denomina 'custos de transação'. Instituições fortes facilitariam a coordenação do sistema econômico ao reduzir os custos de transação e amenizar as incertezas (NORTH, 1990, p. 27).

NORTH, Institutions, Institutional Change and Economic performance, p.36.
} 
que, ainda segundo North, seria possível explicar com base nas diferenças de desenvolvimento institucional a partir do século XIX os distintos níveis de desenvolvimento econômico alcançados pelos Estados Unidos em comparação com os países da América Latina ${ }^{\square}$. Para além disto, uma outra coordenada importante a ser aqui considerada refere-se às diferenças de recepção que cada sociedade historicamente localizada apresentou em relação à implantação e transformações de cada modelo institucional ${ }^{12}$. As explicações proporcionadas pela análise de North, por outro lado, vinculam-se às discussões e polêmicas que se dão em torno do pensamento econômico liberal contemporâneo. Eis aqui, de todo modo, questões que mereceriam certamente um desenvolvimento mais aprofundado em outro artigo.

Seria possível citar, de outro lado, uma ampla historiografia marxista igualmente atenta à complexidade histórico-social na análise de processos econômicos. Um nome que ressalta nesta busca de complexidade é o de Edward Thompson, um historiador bastante atento aos imbricamentos entre fatos econômicos, políticos e culturais. Sua obra sobre a Formação da Classe Operária Inglesa é bastante exemplar neste sentido, mas uma obra de tal envergadura requereria, naturalmente, um estudo à parte ${ }^{\square}$

Por outro lado é importante destacar que, notadamente com a historiografia marxista e outras preocupadas com a dimensão social da História, considera-se que o sistema de produção está em inseparável interface com a organização social e política de uma sociedade. Daí que, para este tipo de história econômica, é imprescindível caminhar conjuntamente com a História Social e com a História Política. Qualquer grupo social ocupa uma posição - central ou periférica, ativa ou parasitária, consciente ou alienada - no sistema de produção de uma sociedade, e todos estabelecem entre si relações que, além de sociais, são relações políticas. Para o materialismo histórico, por exemplo, a História é a história dos modos de produção e também a história das lutas de classe. Uma coisa está sobreposta à outra, pois se os modos de produção vão se desenvolvendo e derivando em outros no decurso de uma duração mais longa, a luta de classes aflora cotidiana e conjunturalmente sobre estas grandes estruturas em mutação. Percebe-se assim que, nesta linha de perspectivas, a História Econômica está em

${ }_{12}$ Vale lembrar ainda o diagnóstico de North para a história dos países da América Latina, que desde a época colonial teriam apresentado uma tendência da personalização das relações comerciais entre indivíduos, afastando estas sociedades da criação de mecanismos formais eficientes (isto é, do fortalecimento institucional). 
permanente interface com uma História Política e uma História Social. Não é possível examinar um determinado processo histórico, neste sentido, sem investir na complexidade de uma textura social que envolve aspectos econômicos, sociais, políticos, ou mesmo culturais, como demonstrou tão bem Edward Thompson.

\section{CIRCULAÇÃO E CONSUMO - DOIS OUTROS FOCOS DE ATENÇÃO}

O enfoque do historiador econômico também pode se dirigir para a esfera da Circulação (ou da distribuição). Serão estudados aqui os ciclos econômicos, os preços, as trocas, o sistema financeiro. Considerar a circulação ou a distribuição envolve, para além das óbvias considerações pertinentes à estratificação social, uma atenção às tendências culturais e aos movimentos de mentalidade. De todo modo, o interesse no estudo dos ciclos econômicos tornou-se muito marcante a partir da década de 1930, com historiadores da economia associados à Escola dos Annales (mas neste caso também ao marxismo) como Ernst Labrousse. Destaca-se uma interface evidente da nova História Econômica com os diversos desenvolvimentos na ciência social da Economia, e essa foi uma interdisciplinaridade bastante importante conquistada pelos historiadores econômicos da primeira metade do século XX. Para além disto, o estudo dos ciclos, das conjunturas, da flutuação de preços e salários (e tantos outros aspectos) tornou-se possível a partir do diálogo com a Estatística. Estes novos campos da História Econômica tornam-se precisamente possíveis com a quantificação - com aquela abordagem que logo passaria a ser chamada de História Quantitativa.

Fechando o circuito de interesses da História Econômica aparece a esfera do Consumo, com objetos que podem ir desde os aspectos relativos aos salários (poder de compra) até os hábitos de consumo dos vários grupos sociais. Estudar o consumo é estudar os modos como a riqueza é apropriada pelos vários grupos e forças sociais que se encontram em interação no interior de uma determinada sociedade. As tensões sociais, enfim, também se expressam nas relações de consumo, nas ostentações, nas carências, nos contrastes que dão a revelar a riqueza apropriada e que a colocam em contraposição à riqueza produzida. Esta ponta do triângulo econômico, por- 
tanto, estabelece uma interface com a História Social. Desnecessário dizer que a própria História Cultural, fundamental para a compreensão complexa das tendências do consumo e das múltiplas formas de apropriação dos bens produzidos pelas diversas classes sociais, torna-se também aqui uma parceira inevitável para a História Econômica. Separar âmbitos de estudo centrados no Econômico, Cultural ou Político, a bem da verdade, não é possível senão como uma referência de base, pois a própria complexidade da história humana estabelece naturalmente interfaces entre estas diversas dimensões da vida humana.

\section{COMPLEXIDADE RÍTMICA E COMPLEXIDADES LOCAIS}

Para além da complexidade dos processos econômicos como produtos de interações entre aspectos para além do "econômico" propriamente dito, há que se considerar ainda a complexidade rítmica dos processos econômicos. Assim, outro aspecto fundamental sobre o qual deve refletir o historiador econômico que se lança a uma investigação refere-se ao questionamento acerca da sincronicidade de fatos econômicos relativamente a uma determinada unidade de observação. Deve-se considerar a possibilidade de que haja diferenças de ritmo entre distintos setores econômicos de um mesmo país ou região, por exemplo, em contraste com a idéia de que na economia de uma determinada sociedade todos os seus elementos evoluem ou desenvolvem-se consoante ritmos idênticos.

De igual maneira, em se tratando de estudos nacionais, as diversas pesquisas realizadas por historiadores econômicos regionais têm mostrado que não é possível enquadrar os desenvolvimentos econômicos nas diversas regiões de um país no âmbito de um único perfil econômico. Os antigos modelos explicativos que buscavam dar conta da totalidade da economia ao nível nacional começaram, em muitos países, a serem confrontados pela realização de trabalhos empíricos realizados ao nível regional, que obrigaram a sérias revisões relativamente a modelos generalizantes que antes eram admitidos sem contestação.

Foi o que ocorreu no Brasil a partir dos anos 80, e sobretudo dos anos 90, com uma série de trabalhos sobre a Sociedade Escravocrata no Brasil, onde foi confrontado o antigo modelo da Monocultura Agro-Exportadora 
voltada única ou preponderantemente para o mercado externo ${ }^{13}$, e na qual o escravo desempenhava um papel específico de um tipo de unidade produtiva e de hierarquia que parecia dicotomizar as posições entre Senhores e escra$\operatorname{vos}^{14}$. As investigações ao nível regional permitiram que se verificassem inúmeros fatores importantes como a importância do mercado interno, a eventual diversificação de culturas, o papel dos homens livres pobres na economia e na sociedade escravocrata ${ }^{15}$, as estratégias de negociação dos escravos no interior da sociedade que os oprimia e do sistema econômico que os incorporava como força de trabalho ${ }^{16}$. Para além disto, estas mesmas monografias também revelaram toda uma diversidade inter-regional que os grandes modelos econômicos explicativos nem sempre previam.

\section{A ASSIMILAÇÃO DAS COMPLEXIDADES DA HISTÓRIA ECONÔMICA NA HISTORIOGRAFIA BRASILEIRA}

Para prosseguir com o exemplo da História do Brasil, é importante lembrar que a História Econômica entre nós tem sido desde os anos 1930 um campo bem freqüentado pelos historiadores brasileiros. Os objetos e interesses de estudo começam a se diversificar bastante já desde a primeira metade do século XX, e é possível mencionar mais destacadamente, ao lado

\footnotetext{
13 Em um artigo de 1985 no qual analisa a economia mineira da segunda metade do século XIX, Robert Slenes chama atenção para a diversificação econômica daquela região, para a produção de gêneros voltada para o mercado interno, e para o dinamismo da economia não-exportadora (SLENES, Robert. "Os múltiplos de porcos e diamantes: a economia escravista de Minas Gerais no século XIX". Cadernos ICHL/UNICAMP, Campinas, n. 17, 1985). De igual maneira, no âmbito de pesquisas que evidenciam a diversificação da economia colonial, podemos citar, entre outros, o trabalho de Hebe Castro, que, ao analisar um município fluminense do século XIX, pôde perceber para os maiores produtores locais uma diversificação de produção especificamente voltada para o mercado local (CASTRO, Hebe Maria Mattos de. Ao Sul da História. São Paulo: Brasiliense, 1987).

14 Assim, por exemplo, a tese de Mary Karasch sobre a vida dos escravos no Rio de Janeiro (1988) já chama atenção para a presença importante de pequenos senhores que, na sociedade escravocrata, possuíam apenas um ou dois escravos, o que permitia confrontar o modelo dicotômico que aos escravos opunha apenas o grande latifundiário proprietário de inúmeros escravos, ignorando todo um contingente de pequenos senhores (KARASCH, Mary. A Vida dos Escravos no Rio de Janeiro. São Paulo: Companhia das Letras, 2000). Pesquisas como esta, e também a de Stuart Schwartz para o Recôncavo Baiano, confrontavam a idéia de que a propriedade escrava apresentava-se radicalmente concentrada no nas mãos de grandes proprietários de terras (SCHWARTZ, Stuart. "Padrões de propriedades de escravos nas Américas: nova evidência para o Brasil”, Estudos Econômicos, XIII, n I, 1983, p.259-287).

15 Uma referência já clássica para este aspecto é a obra de 1969 produzida por Maria Sylvia de Carvalho Franco sobre os Homens Livres na Ordem Escravocrata (São Paulo: UNESP, 1994), certamente um trabalho pioneiro que já chamava atenção para uma questão que seria cada vez mais abordada nas décadas seguintes.

16 A esse respeito, tem-se um marco importante com o livro Campos da violência de Sílvia Lara (Rio de Janeiro: Paz e Terra, 1988). Mais ainda, é fundamental a referência à obra conjunta de João José REIS e Eduardo SILVA intitulada. Negociação e conflito: a resistência negra no Brasil escravista (São Paulo: Companhia das Letras, 2005).
} 
de outras temáticas, as tentativas de elaborar grandes modelos econômicos globais que dessem conta de entender a história econômica brasileira como uma totalidade. Surgiram então grandes modelos explicativos para a realidade colonial, para a sociedade escravista-colonial, para a economia no Estado Novo ou do período desenvolvimentista, através de autores que vão de Caio Prado Júnior, um pioneiro na área, até historiadores, economistas ou sociólogos como Fernando Novais, Celso Furtado, Ciro Flamarion Cardoso, Jacob Gorender ${ }^{17}$. As últimas décadas do século XX assistem, conforme já foi apontado, à eclosão de trabalhos mais monográficos, interessados em perceber através de investigações locais - muitas vezes com o apoio da História Serial - precisamente aquelas especificidades e complexidades que os grandes modelos explicativos deixavam escapar, por vezes em fórmulas ou modelos reducionistas.

Desta lavra, e das décadas seguintes, são alguns dos mais importantes trabalhos sobre a economia brasileira nos seus períodos históricos. Há desde as investigações regionais ou mais localizadas sobre o período escravocrata, como a obra de Kátia Matoso intitulada "Bahia: a cidade de Salvador e seu mercado no século XIX” (1978) ${ }^{18}$, ou a obra de Douglas Libby sobre a "Transformação e Trabalho em uma economia escravista - Minas no século XIX" (1988) ${ }^{19}$, até as investigações de recorte mais extenso sobre o processo de industrialização brasileiro, como a pesquisa de Wilson Cano sobre as "Raízes da Concentração Industrial" (1981) ${ }^{20}$ ou a obra de Geraldo Beauclair sobre as "Raízes da Indústria no Brasil""21. No âmbito dos estudos sobre a Escravidão ou ambientados na Economia Colonial, a massa crítica de trabalhos regionais e a possibilidade mais concreta de lançar mão da História Serial passou a permitir também novas visões de conjunto, mais fundamentadas e sem os reducionismos das generalizações anteriores aos

17 ( I) PRADO JÚNIOR, Caio. Formação do Brasil Contemporâneo. São Paulo: Brasiliense, 1977. (2) NOVAIS, Fernando A. Portugal e Brasil na crise do Antigo Sistema Colonial. São Paulo: Hucitec, 1983, $2^{\text {a }}$ ed. (3) FURTADO, Celso. Formação Econômica do Brasil. São Paulo: Companhia Editora Nacional, 1976. (4) CARDOSO, Ciro Flamarion. "Observações sobre o dossier preparatório da discussão sobre o modo de produção colonial" in PARAIN, C (org). Sobre o Feudalismo. Lisboa: Estampa, 1973, p. 7 I-ss. (5) GORENDER, Jacob. O Escravismo Colonial. São Paulo: Ática, 1978, $2^{\mathrm{a}}$ ed.

18 MATTOSO, Kátia de Queiroz. Bahia: a cidade de Salvador e seu mercado no século XIX. São Paulo: Hucitec, 1978.

19 LIBBY, Douglas. Transformação e Trabalho em uma economia escravista - Minas no século XIX. São Paulo: Brasiliense, 1988.

${ }^{20}$ CANO, Wilson. Raízes da Concentração Industrial. São Paulo: T. A. Queiroz, | 98 |.

21 BEAUCLAIR, Geraldo. Raízes da Indústria no Brasil. Rio de Janeiro: Studio F \& S Editora, 1992. 
anos 1970. Aparecem aqui obras importantes como o estudo de João Fragoso e Manolo Florentino intitulado "Arcaísmo como Projeto" 22 , e posteriormente o estudo de João Fragoso sobre a economia local do Rio de Janeiro que, conforme veremos adiante, avança pela trilha que começara a ser percorrida por autores como Kátia Mattoso nos anos 1970 e 1980.

\section{UM EXEMPLO FINAL: O ESTUDO DA ECONOMIA COLO- NIAL NO BRASIL}

A título de exemplo, examinaremos alguns desenvolvimentos historiográficos em torno da temática da economia colonial, mostrando como foi precisamente um olhar mais atento para a complexidade e para a realidade local, alicerçado em sistemáticas pesquisas empíricas, o que permitiu uma verdadeira revisão dos modelos generalizantes que, antes dos anos 70, vinham sendo elaborados para a compreensão da economia brasileira no período colonial. Ao lado do já mencionado trabalho de Kátia Mattoso sobre a Bahia, traremos o exemplo de uma obra que representa certamente um marco para a historiografia econômica brasileira mais recente: o estudo de João Fragoso intitulado "Homens de Grossa Aventura - acumulação e hierarquia na praça mercantil do Rio de Janeiro (1790-1830)"23. Esta obra, como a de Kátia Mattoso e outras, permitiu precisamente à nova historiografia econômica brasileira examinar os ritmos internos da economia colonial, suas assincronias em relação ao mercado internacional, suas diversidades regionais, suas complexidades irredutíveis ao desgastado e generalizador modelo que retratava a economia colonial como um sistema exclusivamente escravista-agro-exportador, diretamente dependente dos centros europeus.

Objetivando examinar as formas de acumulação que perpassam a economia colonial brasileira em fins do século XVIII e primeiras décadas do século XIX, Fragoso elege como lócus privilegiado de observação o funcionamento do mercado do Rio de Janeiro e suas formas de produção. Mas, sobretudo, o que aqui se empreende é mais uma contribuição à vigorosa crítica em relação aos antigos modelos explicativos da economia colonial brasileira, alcançada através da exposição de uma série de novas comple-

22 FLORENTINO, Manolo e FRAGOSO, João. Arcaísmo como Projeto. Rio de Janeiro: Diadorin, 1993.

23 FRAGOSO, João. Homens de Grossa Aventura - acumulação e hierarquia na praça mercantil do Rio de Janeiro ( 1790 1830). Rio de Janeiro: Civilização Brasileira, 1998. 
xidades que se tornam bastante claras a partir de uma bem fundamentada pesquisa empírica amparada em análises seriais de uma vasta documentação.

A primeira complexidade a ser examinada é a de que a economia colonial brasileira apresenta através dos números levantados um complexo jogo de ajuste e desajuste em relação ao ciclo econômico internacional. Ao invés de uma economia inteiramente atrelada ao ritmo internacional, o autor vem mostrar que - ainda que esta sintonia se expresse em algumas oportunidades - a economia colonial brasileira também tem seus ritmos próprios. A consciência de que os ritmos coloniais não se ajustam inteiramente e em todos os momentos às tendências internacionais já vinha sendo expressa através das pesquisas de Kátia Mattoso, que examinara através de uma sistemática metodologia quantitativa os preços na Bahia do mesmo período, demonstrando seu comportamento de acordo com ritmos próprios ${ }^{24}$. Assim, enquanto os preços europeus haviam sofrido uma inflexão geral "para cima" entre 1810 e 1815, até atingir neste ano a crise mundial que inaugura uma fase depressiva, esta inflexão só ocorreria na Bahia a partir de 1822.

O objetivo de Fragoso é seguir nesta mesma trilha: demonstrar que também o Rio de Janeiro tinha seus ritmos próprios. O recorte da pesquisa situa-se no enquadramento de um ciclo de Kondratieff que tem uma "fase A" positiva entre 1792 e 1815, e uma fase negativa (B) entre 1815 e 1850. Contudo, se por um lado verifica-se a sintonia entre uma expansão econômica brasileira e a ampliação do comércio no plano internacional, já para o período seguinte (a fase B) esta sintonia não se verifica. Entre 1815 e 1817, ocorre uma crise mundial que se expressaria sob a forma de uma depressão econômica até 1850, afetando diretamente os preços do açúcar e do algodão. Conforme a interpretação clássica, a montagem da economia cafeeira apresenta-se como uma resposta ao declínio destes produtos e à conjuntura econômica internacional desfavorável.

O modelo confrontado e criticado pelo autor (e mais especificamente considerando o contexto específico das transformações que se dão na passagem do século XVIII para o século XIX) é o da economia colonial exclusivamente fundada na monocultura exportadora, destinada a fornecer excedentes para as economias centrais européias. Segundo este modelo, não

24 MATTOSO, Kátia de Queiroz. "Os preços na Bahia de 1750 a 1930" in L'Histoire quantitative du Brésil de 1800 a 1930, CIVRS 1973, p. 167-182. 
haveria lugar na colônia para um mercado interno suprido por produções locais, nem para possibilidades de acumulações endógenas, e tampouco para ritmos econômicos próprios, desvinculados das economias que dominavam o mercado internacional ${ }^{25}$. Contudo, são precisamente estes aspectos que Fragoso verifica, mostrando por exemplo que o comportamento da economia colonial não pode ser medido apenas pelo desempenho do setor exportador. Assim, contra uma queda de preços de produtos ligados ao setor exportador, como o açúcar branco, Fragoso demonstra uma realidade diferente relativa aos produtos coloniais de abastecimento que desembarcam no porto do Rio de Janeiro ${ }^{26}$. Sintetizando a questão, o mercado interno colonial produz os seus próprios ritmos, que interagem de muitas maneiras com os ritmos ditados pelo mercado internacional, respondem ou resistem a eles. O mercado interno, portanto, é uma realidade efetiva, importante para a compreensão da história econômica. Conforme as palavras de Fragoso, "a economia colonial é um pouco mais complexa do que uma plantation escravista, submetida aos sabores das conjunturas internacionais" ${ }^{27}$. É todo um antigo modelo interpretativo, demasiado simplificador, que aqui se questiona. Mais ainda, diante da verificação empírica de uma verdadeira flexibilidade da economia colonial que a permite confrontar-se à queda de preços internacionais e à retração da exportação, Fragoso identifica a possibilidade de realização de acumulações endógenas no espaço colonial, um dos objetivos centrais de seu estudo. Questionam-se, também, as postuladas relações de estrita dependência que, segundo antigos modelos explicativos, estariam necessariamente presentes nas relações da economia colonial com a Metrópole.

Vale ressaltar, por outro lado, que o trabalho de João Fragoso se refere mais especificamente à virada do século XVIII para o século XIX - um período de crise do antigo sistema colonial. Para os três séculos anteriores de colonização da América portuguesa, decerto, o modelo de análise econômica proposto por Caio Prado Júnior e seguido de perto por Celso Furtado e Fernando Novaes conserva considerável poder explicativo. De todo modo, as obras de João Fragoso e Kátia Mattoso foram aqui evocadas apenas como suporte exemplificativo. Elas constituem sintomas claros de uma historiografia brasileira em pleno desenvolvimento e renovação, que se

${ }^{25}$ FRAGOSO, João. Op.cit. p.16-17.

26 FRAGOSO, João. Op.cit. p.20.

27 FRAGOSO, João. Op.cit. p.21. 
liberta de modelos fechados e irredutíveis, que busca novas complexidades e que, sobretudo, empreende um trabalho sistemático sobre as fontes a partir do uso de uma metodologia quantitativa e serial que mostra perfeita vitalidade. A História Econômica, particularmente no Brasil, está longe de estar em crise. Outras obras poderiam ser citadas, mas estas já podem dar uma idéia da fecundidade deste campo que, mesmo que tenha cedido espaço no conjunto de preferências dos historiadores em favor de outras modalidades em ascensão, permanece francamente atualizado e produtivo.

\section{CONCLUSÃO.}

A História Econômica, será oportuno finalizar, tem se apresentado como um campo que se renova e atualiza. Desenvolve-se no sentido da complexidade, da superação das visões simplificadas que habitualmente isolam os fatos econômicos de outras dimensões importantes para a História das Sociedades como a Política ou a Cultura. De igual maneira, os historiadores econômicos mostram-se cada vez mais atentos à questão de que em cada período histórico, ou em cada sociedade historicamente localizada, deve-se buscar uma racionalidade econômica própria e específica do período examinado, e não simplesmente transplantar uma racionalidade capitalista para períodos anteriores nos quais esta racionalidade não existia. Avança-se também na superação dos antigos modelos explicativos nacionais monolíticos, à medida que se desenvolvem estudos regionais capazes de esclarecer a singularidade de cada região em um contexto mais amplo.

\section{TRANSFORMATIONS IN ECONOMIC HISTORY: CONSIDER- ATIONS ON CHANGES IN ECONOMIC MODELS THROUGH HISTORY}

\section{Abstract}

This article intends to develop some considerations about the Economic History, as a singular modality of historical knowledge, and its methodological postures on the analysis of historiographical subjects. The specific question treated refers to the reflection of this field on the 
main characteristic of the changes of one economic system into another one, or deals with a great pattern typical of a certain time, in a certain region, of a new pattern.

Keywords: Economic History; Social-Economic History; Economics

JEL Classification: B00; N01

\section{REFERÊNCIAS}

BEAUCLAIR, Geraldo. Raízes da Indústria no Brasil. Rio de Janeiro: Studio F \& S Editora, 1992.

CANO, Wilson. Raízes da Concentração Industrial. São Paulo: T. A. Queiroz, 1981.

CARDOSO, Ciro Flamarion e BRIGNOLI, Héctor Pérez. Os Métodos da História. Rio de Janeiro: Graal, 1990.

CARDOSO, Ciro Flamarion. "Observações sobre o dossier preparatório da discussão sobre o modo de produção colonial" in PARAIN, C (org). Sobre o Feudalismo. Lisboa: Estampa, 1973, p. 71-ss.

CARDOSO, Ciro Flamarion e BRIGNOLI, Héctor Pérez. Os Métodos da História. Rio de Janeiro: Graal, 1990, p.278-279.

CASTRO, Hebe Maria Mattos de. Ao Sul da História. São Paulo: Brasiliense, 1987.

CLAPHAM, J. H. An Economic History of Modern Britain. 3 vol. 19261938.

DOBB, Maurice. Studies in the Development of Capitalism. Londres: Intl Pub, 1964 [original: 1946] 
DOBB, Maurice. "Uma Réplica", Science and Society. Londres: spring, 1950. republicada em HILTON, Rodney (org.). A Transição do Feudalismo para o Capitalismo. Rio de Janeiro: Paz e Terra, 1989. p.57-66.

DOBB, Maurice. "Um Comentário Suplementar", Science and Society. Londres: spring, 1953. republicada em HILTON, Rodney (org.). A Transição do Feudalismo para o Capitalismo. Rio de Janeiro: Paz e Terra, 1989. p.97-100. [original da coletânea: 1976].

FLORENTINO, Manolo e FRAGOSO, João. Arcaísmo como Projeto. Rio de Janeiro: Diadorin, 1993.

FRAGOSO, João. Homens de Grossa Aventura - acumulação e hierarquia na praça mercantil do Rio de Janeiro (1790-1830). Rio de Janeiro: Civilização Brasileira, 1998.

FRANCO, Maria Sylvia de Carvalho. Homens Livres na Ordem Escravocrata . São Paulo: UNESP, 1994. 4ª ed [original: 1969].

FURTADO, Celso. Formação Econômica do Brasil. São Paulo: Companhia Editora Nacional, 1976.

GORENDER, Jacob. O Escravismo Colonial. São Paulo: Ática, 1978, $2^{\text {a }}$ ed. HILTON, Rodney (org.). A Transição do Feudalismo para o Capitalismo, Rio de Janeiro: Paz e Terra, 1989.

JEVONS, Williams Stanley. The Solar Period and the Prince of Corn. London: 1875.

JEVONS, W. Stanley. The Periodicity of Commercial Crises and Its Physical Explanation. London: 1878.

JEVONS, W. Stanley. “Commercial Crises and Sun-Spots”. Nature, XIX, nov 1878. 
JEVONS, W. S., Investigations in Currency and Finance, London: Macmillan, 1884.

JEVONS, H. S., "Trade fluctuations and solar activities", Contemporary review, August, 1909.

JEVONS, H. S. The Sun's heath and trade activity. London: 1910.

JUGLAR, C. Des crises comerciales. Paris: 1889. $2^{\mathrm{a}}$ edição.

KARASCH, Mary. A Vida dos Escravos no Rio de Janeiro. São Paulo: Companhia das Letras, 2000.

LABROUSSE, Ernst. Histoire économique et sociale de la France. Paris: Puf, 1979.

LABROUSSE, Ernest. Esquisse du mouvement des prix et des revenus en France du XVIII siècle. 2 vol. Paris: 1932.

LABROUSSE, Ernest. La crise de l'économie française à la fin de l'ancien régime e au début de la Revolution. Paris: 1944.

LARA, Silvia H. Campos da violência. Rio de Janeiro: Paz e Terra, 1988.

LIBBY, Douglas. Transformação e Trabalho em uma economia escravista - Minas no século XIX. São Paulo: Brasiliense, 1988.

MATOSO, Kátia de Q. Bahia: a cidade de Salvador e seu mercado no século XIX. São Paulo: Hucitec, 1978.

MATTOSO, Kátia de Queiroz. “Os preços na Bahia de 1750 a 1930” in L'Histoire quantitative du Brésil de 1800 a 1930, CIVRS 1973, p.167-182.

MITCHELL, W. C. Business Cycles. The Problem and its Setting. 1927. 
NORTH, Douglass. Empirical Studies in Institutional Change (Political Economy of Institutions and Decisions). New York: Lee J. Alston, 1996.

NORTH, Douglass. Institutions, Institutional Change and Economic performance. Cambridge: Cambridge University Press, 1990.

NORTH, Douglass. Structure and Change in Economic History. New York: Norton, 1981.

NOVAIS, Fernando A. Portugal e Brasil na crise do Antigo Sistema Colonial. São Paulo: Hucitec, 1983.

PIRENNE, Henri. Historia de Europa, desde las invasiones al siglo XVI. México: Fondo de Cultura, 1981.

PRADO JÚNIOR, Caio. Formação do Brasil Contemporâneo. São Paulo: Brasiliense, 1977.

REIS, João José e SILVA, Eduardo. Negociação e conflito: a resistência negra no Brasil escravista. São Paulo: Companhia das Letras, 2005.

SCHWARTZ, Stuart. "Padrões de propriedades de escravos nas Américas: nova evidência para o Brasil”, Estudos Econômicos, XIII, n¹, 1983, p.259-287.

SLENES, Robert. "Os múltiplos de porcos e diamantes: a economia escravista de Minas Gerais no século XIX". Cadernos ICHL/UNICAMP, Campinas, n. 17, 1985.

SWEEZY, Paul. "Uma Tréplica", Science and Society. Londres: spring, 1953. republicada em HILTON, Rodney (org.). A Transição do Feudalismo para o Capitalismo. op.cit., 1989. p.101-107.

SIMIAND, François. Recherches anciennes et nouvelles sur le mouvement général des prix, du XVI au XX siècle. Paris : Do,at-Montchrestien, 1932. 
SIMIAND, François. Le salaire, l'ecolution sociale et la monnaie. E vol. Paris : Alcan, 1932.

THOMPSON, Edward. Formação da Classe Operária Inglesa. Rio de Janeiro: Paz e Terra, 1989. 3 vol.

Artigo submetido para publicação em fevereiro de 2010 e aceito em junho de 2010. 